\title{
Relações interpessoais na escola e o desenvolvimento local
}

\author{
Interpersonal relationships in school and the local development
}

Relaciones interpersonales en la escuela y el desarrollo local

\author{
Samira Fakhouri Baia ${ }^{1}$ \\ Lucília Regina de Souza Machado²
}

Recebido em 18/01/2019; revisado e aprovado em 10/07/2019; aceito em 06/08/2019

DOI: http://dx.doi.org/10.20435/inter.v22i1.2355

\begin{abstract}
Resumo: As relações interpessoais na escola são um elemento importante na constituição do desenvolvimento local. Elas são reveladoras da dinâmica territorial com respeito às situações de desagregação decorrentes da busca de afirmação de interesses de grupos, mas também denotam os bons feitos das pretensões de fazer conviver com harmonia as diversidades culturais e a construção das identidades. Este artigo traz resultados de revisão teórica interessada em conhecer conceitos e abordagens sobre relações interpessoais na escola e propostas educacionais de enfrentamento desse desafio. Três das principais conclusões encontradas: os problemas de relacionamento que afetam a convivência na escola e o desenvolvimento local têm origem primordial na estrutura social; a violência e a intolerância, em quaisquer graus, afetam os direitos humanos e as possibilidades da inclusão social pela educação; há experiências concretas que mostram ser possível melhorar as relações interpessoais na escola.
\end{abstract}

Palavras-chave: relações interpessoais na escola; violência na escola; direitos humanos; desenvolvimento local.

Abstract: Interpersonal relationships in school are an important element in the constitution of local development. They are revealing of the territorial dynamics concerning the situations of disaggregation resulting from the search for the assertion of group interests, but they also denote the good deeds of the pretensions of making harmony with cultural diversities and the construction of identities. This article brings theoretical review results interested in knowing concepts and approaches on interpersonal relationships in the school and educational proposals to face this challenge. Three of the main conclusions found: the relationship problems that affect the coexistence in the school and the local development have primordial origin in the social structure; violence and intolerance, to any degree, affect human rights and the possibilities of social inclusion for education; there are concrete experiences that show that it is possible to improve interpersonal relationships in school.

Keywords: interpersonal relationships in school; violence in school; human rights; local development.

Resumen: Las relaciones interpersonales en la escuela son un elemento importante en la constitución del desarrollo local. Ellas son reveladoras de la dinámica territorial con respecto a las situaciones de desagregación derivadas de la búsqueda de afirmación de intereses de grupos, pero también denotan los buenos hechos de las pretensiones de hacer convivir con armonía diversidades culturales y la construcción de las identidades. Este artículo trae resultados de revisión teórica interesada en conocer conceptos y enfoques sobre relaciones interpersonales en la escuela y propuestas educativas de enfrentamiento de ese desafío. Tres de las principales conclusiones encontradas: los problemas de relación que afectan a la convivencia en la escuela y el desarrollo local tienen un origen primordial en la estructura social; la violencia y la intolerancia, en cualquier grado, afectan los derechos humanos y las posibilidades de la inclusión social por la educación; hay experiencias concretas que muestran que es posible mejorar las relaciones interpersonales en la escuela.

Palabras clave: relaciones interpersonales en la escuela; violencia en la escuela; derechos humanos; desarrollo local.

\section{INTRODUÇÃO}

Este artigo relata uma revisão de literatura sobre o tema das relações interpessoais na escola. Realizada como parte de uma investigação para fins de conclusão de um mestrado, esta revisão teve como objetivo conhecer conceitos, abordagens e experiências educacionais acerca

\footnotetext{
${ }^{1}$ Escola Estadual José de Alencar, Macapá, Amapá. Brasil.

${ }^{2}$ Universidade Federal de Minas Gerais, Belo Horizonte, Minas Gerais, Brasil.
} 
deste tema, tendo em vista a sistematização de uma proposta de intervenção educacional inovadora socialmente e capaz de contribuir para a sustentação do desenvolvimento local.

Relações interpessoais, segundo Antunes (2014, p. 9), são “[...] o conjunto de procedimentos que, facilitando a comunicação e as linguagens, estabelece laços sólidos nas relações humanas". Para o autor, as relações interpessoais têm bases emocionais e psicopedagógicas e podem criar um clima favorável na escola, ou não.

Ao conceber a formação da individualidade como processo social, Vigotski considera que o modo de ser de um sujeito é influenciado pela relação que ele estabelece com os outros. 0 autor afirma que "Através dos outros constituímo-nos" (VIGOTSKI, 2000, p. 24).

Essa proposição de Vigotski sobre o papel fundante das relações sociais na formação do sujeito tem implicações importantes, pois significa compreender que a personalidade de cada um se faz em sociedade, um processo que requer igualmente a atividade interna de cada sujeito para se reunir com os demais, sem, contudo, deixar de se diferenciar nas suas atitudes e formas de interpretar normas, direitos e deveres que as condicionam e explicam. Nesse sentido, para o autor, a linguagem exerce uma mediação simbólica essencial nas relações do indivíduo com o grupo social, pois ela traz os significados sociais que têm a função de regular as ações humanas.

Nesses termos, entende-se que os membros de um grupo social se concernem e se influenciem reciprocamente. Considera-se, ainda, que esse grupo social, não estando fechado em si mesmo, guarda inter-relações com outros, tratos que podem ou não ser de afinidade, afeição ou camaradagem, mas que sempre se fazem presentes na vida de cada sujeito em particular.

Logo, as relações sociais, que alicerçam e constituem os processos individuais, são desenhadas por acordos, compatibilidades, simetrias, partilhas e solidariedades, mas também por imposições, coações, tensões, conflitos e contradições, o que significa que estão sempre em equilíbrio instável.

Tais interações, configuradas pelos diferentes lugares sociais onde se encontram os sujeitos e suas maneiras de se colocar na vida em sociedade, na cultura e na representação de papéis sociais, condicionam a construção social deles próprios e dos outros com os quais se relacionam. Elas não se limitam imediatamente à condição do visível, seja com respeito ao que cada um age diante do outro, seja do que é dito nessas interações. Há outras dimensões dessa intervenção mútua, que não se processam de forma palpável, física, presencial, tais como as normas, os códigos, os personagens que são tidos como exemplares do positivo ou negativo, as figuras-tipo de cada cultura.

Vigotski se faz, assim, tributário da concepção materialista, histórica e dialética de Marx e Engels apresentada n'A Ideologia Alemã (1982), em que deixam registrada esta crítica a Feuerbach:

[...] fica-se pela abstracção de "o Homem", e só consegue reconhecer o "homem corpóreo, individual, real" no sentimento, ou seja, não conhece outras "relações humanas" "do homem com o homem" além de amor e amizade, e mesmo assim idealizados. (MARX; ENGELS, 1982, s.p.).

Já nas Teses sobre Feuerbach, Marx diz textualmente naquela que leva o número seis: "[...] a essência humana não é uma abstração inerente a cada indivíduo. Na sua realidade ela é o conjunto das relações sociais" (MARX, 1982, s.p.).

Com base nesses fundamentos, entende-se que é preciso buscar no contexto da estrutura social brasileira, no cenário atual das transformações nos campos social, cultural, econômico e 
político e da forma como alunos e professores estão neles inseridos e se relacionam, os elementos que permitam compreender as questões referentes às relações interpessoais na escola.

Trata-se de um quadro histórico-cultural de uma sociedade capitalista, estruturada por relações sociais de produção marcadas pela desigualdade entre classes sociais, que desfrutam de condições díspares para acessar os bens de toda ordem produzidos socialmente. Essa realidade, por si só, é fator da violência estrutural que repercute nas diversas dimensões da vida, inclusive no interior da instituição escolar.

Diante desse contexto, profissionais da área de educação têm feito indagações, como as de Friedmann:

[...] Quem é o educador para um tempo de mudanças tão rápidas e exigências tão intensas como o nosso? [...] Como levar, através de vivências simples e autênticas, a uma percepção de que o caminho escolhido é possível? (FRIEDMANN, 2004, p. 11).

Como tentativas de respostas a essas questões, diferentes propostas educacionais que visam melhorar os relacionamentos interpessoais têm se desenvolvido diante das possibilidades que se apresentam no cotidiano escolar. A seção seguinte procura avançar na discussão dessa problemática, nos conceitos e abordagens utilizados para analisá-la, bem como algumas tentativas de respostas.

\section{CONCEITOS, ABORDAGENS E PROPOSTAS PARA ENFRENTAR OS DESAFIOS DAS RELAÇÕES INTERPESSOAIS NA ESCOLA}

Uma das propostas que têm sido apontadas para enfrentar os desafios das relações interpessoais na escola é a busca de aporte para a ação docente por meio da "[...] interdisciplinaridade como uma abordagem epistemológica que nos permite ultrapassar as fronteiras disciplinares e nos possibilita tratar, de maneira integrada, os tópicos comuns às diversas áreas" (MORAES, 2007, p. 39).

A prática da interdisciplinaridade tem sido vista como uma estratégia para promover a intercomunicação e a intercompreensão, tendo por base o diálogo e o reconhecimento da legitimidade das diferenças. Com isso, embora não isenta de possibilidades de conflitos, acena para a possibilidade se não das convergências, pelo menos do respeito mútuo. Assim, o tratamento de temas transversais a partir de ângulos diversos poderia abrir as postas para a manifestação do outro. Segundo Moraes (2007, p. 39), "Na prática, a interdisciplinaridade e a transversalidade se fundem, se entrelaçam, numa rede de relações e conexões que ligam os conteúdos disciplinares uns aos outros, inserem estes conteúdos na realidade e no contexto que nos cerca".

Porém, segundo Mentis (1997), professora do Instituto de Educação da Massey University, na Nova Zelândia, é preciso que professores demonstrem interesse sincero pelo educando e busquem se atualizar constantemente, caminhem para desvendar mundos ainda não plenamente compreendidos, para a construção da relação entre educador e educando, na perspectiva de propiciar uma convivência saudável, de reforço à confiança e à segurança de todos.

Ainda, segundo essa autora, divulgadora da teoria da experiência da aprendizagem mediada do romeno Reuven Feuerstein, para formar cidadãos críticos capazes de lidar com todo tipo de mudança e de conflitos interpessoais, de desenvolver elos de confiança nos seus relacionamentos e serem assertivos em encontrar seu rumo na vida, é fundamental instigar o conhecimento de si mesmo e, também, ter uma boa comunicação em casa. E na escola isso não seria diferente (MENTIS, 1997). 
O diálogo seria, assim, uma estratégia eficiente como parte do processo de amadurecimento das ações voltadas à supressão das barreiras à comunicação entre os inúmeros desafios enfrentados a cada dia no ambiente escolar. Segundo Mentis,

[...] a aprendizagem mediada permite ao indivíduo desenvolver habilidades de pensamento eficientes, possibilitando-o tornar-se aprendiz independente e autônomo. A aprendizagem mediada e a cognição podem fazer o trajeto da aprendizagem efetiva. (MENTIS, 1997, p. 13).

Dessa forma, a boa relação entre educador e educando se faz fundamental para o desenvolvimento do aluno. Ela Ihes possibilita não se aterem presos aos problemas recorrentes da sociedade em que vivem, mas encontrarem saídas que lhes permitam contribuir para fortalecer os laços sociais, respeitando-se as diversidades individuais e coletivas.

Não é simples abandonar antigas rotinas estabelecidas, mas isso pode oportunizar a criação de ambientes saudáveis, de colaboração e a reflexão sobre como enfrentar os desafios impostos e como construir espaços sociais coparticipantes, solidários e corresponsáveis.

Embora o aluno aprenda com todos os que compõem o ambiente escolar, incluindo seus próprios colegas, é impossível negar a importância do professor como agente transformador do processo de ensino-aprendizagem. Antunes ressalta que, para isso, o docente precisa enriquecer suas estratégias didáticas, pois, segundo ele:

A aula expositiva convencional é uma estratégia de ensino marcada pela passividade e pela ação extremamente individualista do aluno [...] em que o professor recita em voz alta alguns elementos de seu pensamento interior, como que jogando sementes na esperança de que algumas caiam em solo fértil. A alternância dessa estratégia de ensino com alguns jogos operatórios específicos, altamente cooperativos [...] pode estimular alguns alunos que se interessem pelo êxito de seus colegas [...] é importante destacar que o sucesso do empreendimento depende muito da natureza do desafio proposto pelo professor. [...] A ação do professor programando atividades socializadoras, orientando a intervenção dos alunos mais aptos, constitui fundamento indispensável [...]. (ANTUNES, 2013, p. 43-5).

A perspectiva proposta é de favorecer o relacionamento e as trocas entre os alunos, estimular formas de interação que ampliam os horizontes da convivência escolar, enriquecer as experiências individuais dos discentes, permitir a realização das expectativas dos alunos e auxiliá-los no aprendizado.

Frequentar a escola também é desenvolver a consciência dos valores advindos do compartilhamento das tarefas, da exposição livre de opiniões e pontos de vista, da escuta aos colegas, da amenização dos possíveis conflitos, da cooperação participativa com a coletividade. São habilidades sociais que, dentro ou fora do ambiente escolar, são condições para que todos desfrutem, no contato social, de seus direitos como cidadãos (ANTUNES, 2013).

Assim, o tema das relações interpessoais na escola está indissociavelmente conectado à realização das necessidades educativas fundamentais do desenvolvimento pessoal e intelectual de cada aluno. Isso porque a função social e educativa da escola não se reduz ao mero fornecimento de informações, pois requer a formação integral do sujeito na sua dupla dimensão - inseparáveis entre si -, a individual e a social. Nesse sentido, conforme assegura Paro (2007), a qualidade da educação prevê também a formação da personalidade do educando em sua integralidade, para a qual é imprescindível contar com a liberdade, a pluralidade e a democracia:

Em síntese, o que parece essencial à escola pública de qualidade é que se refira à educação por inteiro, não apenas a aspectos parciais passíveis de aferição mediante provas e exames 
convencionais. Como processo de atualização histórico-cultural, a educação envolve dimensões individuais e sociais, devendo visar tanto ao viver bem pessoal quanto à convivência social, no desfrute de bens culturais como herança histórica que se renova continuamente. A democracia, como meio para construção da liberdade em sua dimensão histórica, faz parte desta herança cultural. Entendida como processo vivo que perpassa toda a vida dos indivíduos, laborando na confluência entre ser humano singular e sua necessária pluralidade social, ela se mostra imprescindível tanto para o desenvolvimento pessoal quanto à convivência livre entre grupos e pessoas e a solução de problemas sociais, colocando-se, portanto, como componente incontestável de uma educação de qualidade. (PARO, 2007, p. 31-2).

Essas observações de Paro dialogam com o atual contexto educacional brasileiro, pelo fato de que muitos jovens consideram desafiador o ambiente escolar. As horas em sala de aula, as constantes avaliações e as muitas lições de casa talvez sejam um campo de testes para sua estrutura mental e emocional, porém essencial para adquirirem habilidades para as diversas situações com que se confrontam e com que se confrontarão (ANTUNES, 2014).

Pais e professores têm, supostamente, como objetivo, incentivar o jovem a se esforçar para atingir todo o seu potencial. Porém, quando ele tem um conceito negativo de si mesmo e dos estudos, isso vem, às vezes, servir de incômodo às suas possibilidades de se sair bem no ambiente escolar.

Para articular as relações entre professor e aluno em sala de aula e promover uma atitude diferente nesse espaço, de valorização das relações interpessoais no contexto didático pedagógico, Antunes adverte:

Não mais deve existir espaço em sala de aula em cuja porta edifica-se o simbólico cabide onde, ao entrar, o aluno ali deixa penduradas as emoções e sentimentos, posto que lá dentro valerá apenas pela lição que faz, atenção com que ouve e nota que tira. (ANTUNES, 2014, p. 13).

É sensato afirmar que, para o aluno, nem todas as matérias do currículo escolar são atraentes, ainda que ele possa ser capaz de compreender que os vários assuntos que lhe são apresentados são meios que lhe permitirão observar melhor o mundo à sua volta, assim como desenvolver as habilidades de raciocinar, descobrir suas potencialidades e explorá-las.

Ouvir de alunos, diante de algum fracasso no seu aprendizado, relatos sobre suas angústias e pensamentos desfavoráveis a respeito de suas habilidades faz parte do ambiente escolar. Pedroza (2012), em publicação do Ministério da Educação, parte do pressuposto de que o professor pode cooperar para a superação desses sentimentos ao trabalhar a valorização do discente, permitindo que reconheça suas fraquezas e potencialize seus pontos fortes.

Diz esse texto que o professor, ao iniciar uma nova situação de ensino-aprendizagem, partindo de uma perspectiva construtivista, deve considerar ser "[...] necessário reconhecer a própria experiência vivida em outros contextos sociais para a construção do conhecimento sobre as relações interpessoais" (PEDROZA, 2012, p. 28).

Isso porque desenvolver bons relacionamentos no ambiente escolar envolve levar em conta o conhecimento prévio do aluno e, a partir dele, elucidar o mundo de possibilidades existentes diante do educando. Nesse sentido, o trabalho coletivo efetuado por alunos e professores em sala de aula pode ser fonte transformadora capaz de identificar os saberes, propor a resolução de tarefas e cooperar para a melhoria dos resultados no aprendizado (PEDROZA, 2012).

$O$ texto lembra que cada aluno tem características pessoais diferentes. Muitos vão se revelar esforçados e com um sentimento favorável em relação ao professor e ao ambiente escolar, com 
maiores possibilidades para rapidamente desenvolver o desejo de aprender e a facilidade de compreender, meio de sustentação para um ambiente mais saudável em sala de aula.

Porém, existem os alunos que revelam ter dificuldade de adaptação e de adequação ao contexto social da escola. Na atualidade, em face das oportunidades oferecidas pelos dispositivos móveis, tendem a ser atraídos pelo que se passa nas redes sociais e na Internet, pelos jogos digitais. Questionados sobre a conveniência de prestar atenção às aulas e realizar as tarefas escolares, podem se mostrar zangados, emburrados, insatisfeitos, tornar-se agressivos e até violentos nas suas reações.

O documento produzido por Pedroza e publicado pelo Ministério da Educação (2012) reitera o crescimento do interesse por possíveis respostas ao desafio educacional de lidar com comportamentos inadequados em sala de aula:

[...] percebe-se a grande procura de respostas por parte da educação em diversas áreas para dar conta da complexidade do fenômeno educativo. Por exemplo, em relação ao comportamento dos alunos em sala de aula, os sérios problemas relacionados à violência e à falta de motivação. (PEDROZA, 2012, p. 27).

Assim, falar de relações interpessoais na escola implica considerá-las como intimamente conectadas às necessidades educativas fundamentais que visam ao desenvolvimento pessoal e intelectual de cada aluno, e, certamente, essas são comprometidas por situações de intolerância, agressão e violência, quaisquer que sejam suas origens e pretensas justificativas.

Michaud define violência considerando a quantidade dos praticantes e dos que a sofrem, o tipo de violência e a extensão causada nas vítimas:

[...] há violência quando, numa situação de interação um ou mais atores agem de maneira direta ou indireta, maciça ou esparsa, causando dano a uma ou mais pessoas em graus variáveis, seja em sua integridade física, seja em sua integridade moral, em suas posses, ou em suas participações simbólicas e culturais. (MICHAUD, 1989, p. 11).

Ao se reportar ao eventual conflito que possa se estabelecer entre a autonomia da vontade do sujeito e a heteronomia dos valores morais, que Ihe são dados como externos porquanto representam os de sua sociedade, Chauí encontra elementos que permitem distinguir o que é violência. Para ela,

[...] ética e violência são opostas, uma vez que violência significa: 1) tudo o que age usando a força para ir contra a natureza de algum ser (é desnaturar); 2) todo ato de força contra a espontaneidade, a vontade e a liberdade de alguém (é coagir, constranger, torturar, brutalizar); 3) todo ato de violação da natureza de alguém ou de alguma coisa valorizada positivamente por uma sociedade (é violar); 4) todo ato de transgressão contra o que alguém ou uma sociedade define como justo e como um direito. (CHAUÍ, 1999, s. p).

Não datam de hoje os registros bibliográficos sobre o fenômeno da violência e agressividade de jovens, seja no plano familiar, seja no percurso da vida escolar, e seus reflexos na vida adulta. Frase atribuída a Sócrates, que viveu no século V a.C., já relatava:

Nossos adolescentes atuais parecem amar o luxo. Têm maus modos e desprezam a autoridade. São desrespeitosos com os adultos e passam o tempo vagando nas praças... São propensos a ofender seus pais, monopolizam a conversa quando estão em companhia de outras pessoas mais velhas; comem com voracidade e tiranizam seus mestres. (SÓCRATES, V séc. a.C. apud LEITE, 2004, p. 4). 
A imputação da autoria desse texto a Sócrates precisa, porém, considerar que esse filósofo ateniense não legou obras escritas, quaisquer que sejam. O que se tem hoje em dia como de sua lavra advém de textos de seus discípulos, especialmente de Platão. Seja como for, a citação acima condiz com as informações que retratam a filosofia de Sócrates como de corte axiológico ou moral, fundada na investigação de uma suposta essência humana, em meio a um contexto histórico de profundas mudanças políticas marcadas pela disputa entre Esparta e Atenas, que requeriam da nova geração atitudes outras.

No caso dos jovens das camadas populares brasileiras, diferentemente do temor que acometia os das famílias aristocráticas atenienses, há um medo inerente ao seu dia a dia decorrente das ameaças e privações causadas pela situação de pobreza, marginalidade e falta de perspectivas.

No Brasil, milhões de jovens acabam sendo vítimas, também, de intimidações na escola. Atormentadores passam dos xingamentos para os maus-tratos físicos. Alguns sofrem ameaças por parte de seus colegas de escola. Atualmente, inclusive, com o auxílio da Internet. A maioria das pessoas que intimidam outras usa palavras, mas não está afastada a possibilidade do emprego da força física. Por meio de agressões, insultos, zombarias e bullying, promovem o sofrimento alheio (SILVA, 2010).

Na publicação com a participação do Ministério da Educação, Pedroza afirma que "[...] a questão da violência na escola vem se constituindo em um problema muito grave. A agressão física, como a verbal, e o desrespeito estão banalizados no cotidiano escolar, como algo consolidado no modo de ser dos jovens" (PEDROZA, 2012, p. 58).

Rodrigues diz que "A Psicologia Social define agressão como qualquer comportamento que tem a intenção de causar danos, físicos ou psicológicos, em outro organismo ou objeto" (RODRIGUES, 2009, p. 190).

Segundo o autor, importa analisar se houve ou não intenção por parte do agente, no caso de querer ou desejar causar dano a outrem, se a ação de agressão ou violência foi premeditada, ou se surgiram fatores alheios à sua vontade. A definição utilizada por Rodrigues (2009) cabe àquele que tem por finalidade causar dano e, de forma concreta comete-o.

As explicações teóricas do surgimento de reações agressivas e violentas, segundo Rodrigues (2009), provêm de bases biológicas e psicológicas e têm fatores sociais, ambientais e pessoais como estímulo. O autor aborda, por exemplo, a influência que a diferente formação familiar de cada um pode ter e os conflitos potenciais que a mescla de fatores pode causar.

Infelizmente, algumas crianças são agressivas porque receberam incentivo para ter um determinado comportamento, como o de provocar os outros, intimidar ou insultar, imaginando serem essas as melhores maneiras de conseguirem o que desejam.

Ao apresentar resultados de pesquisas acerca das ações realizadas por escolas brasileiras tendo em vista oferecer aos alunos uma educação mais prazerosa e com a perspectiva de evitar ou mesmo reduzir os índices de violência no território em que se encontram, especialmente entre os jovens, Abramovay (2004) diz que nas alternativas encontradas foi percebido que:

Valores relacionados à qualidade da relação entre aluno, diretor, professor e a comunidade são trabalhados de forma a incentivar a participação de todos na gestão, segundo uma perspectiva democrática e cidadã. O diálogo mostra-se como peça fundamental nesse processo, que também incorpora à vida escolar expressões culturais dos jovens alunos, freqüentemente ignoradas nas práticas curriculares convencionais. (ABRAMOVAY, 2004, p. 6). 
Nessas últimas, a violência no ambiente escolar, cenas de desrespeito e a transformação dos insultos verbais e das ameaças em agressões físicas, algumas com registro de óbito, são habituais e atingem, sem privilégio, tanto o espaço público como o privado. Violências com causas múltiplas e que se traduzem pela negação do outro e sua exclusão, pela intolerância ao diferente, pela violação dos direitos humanos e que agravam a situação das camadas populares que já sofrem com as desigualdades de renda, com a miséria e as consequências da corrupção endêmica no país.

Fenômeno complexo recorrente, a violência escolar tem se tornado cada vez mais um problema central para a escola, fazendo com que ganhem destaque nos noticiários as tragédias envolvendo alunos, professores, famílias, autoridades e sociedade civil. Um dos relatos sobre casos estudados pela pesquisa coordenada por Abromovay (2004) informa que:

A escola defrontava-se, antes de lançar mão de ações inovadoras, com a violência externa, em um contexto marcado pela presença de galeras, em que o envolvimento de alunos era recorrente. Além disso, não eram raros, no interior da escola, os desentendimentos e as agressões verbais e físicas resultantes de brigas originadas externamente. (ABRAMOVAY, 2004, p. 59).

Ou seja, nem sempre os problemas no ambiente escolar têm sua origem nos relacionamentos entre professores e alunos, mas uma plateia omissa, que não age e que até pode incitar práticas degradantes reproduz a violência de fora da escola e se submete a ela, contribuindo para solidificar as relações conflituosas que são originárias do ambiente escolar.

Gomes (2013) observa gradações; o que inicialmente se apresenta como uma aparente indelicadeza não relevante pode se tornar efetivo ato de violência física, psicológica e social:

[...] as pequenas incivilidades, a indisciplina em sala de aula e no ambiente escolar, o desrespeito interpessoal, expresso através dos desafetos, das discriminações e preconceitos étnico-raciais, de gênero, [...] religiosos e culturais, que por vezes terminavam em enfrentamentos que deixavam, aos poucos, de ser uma simples expressão de agressividade e se transformavam em atos de violência, física, psicológica e social. (GOMES, 2013, p. 10).

Problemas corriqueiros têm sido objeto de atenção e até resolvidos internamente nas escolas brasileiras pela ação gestora, mediante a colocação de grades, cercas, muros mais altos, trancas e cadeados, mas tais iniciativas têm deixado de ser eficazes. Novas medidas acabam sendo tomadas, entre elas, a contratação de seguranças ou a solicitação da ronda da Polícia Militar. E tudo isso vai até na contramão da tentativa de promover uma cultura de não violência como forma de resolução ou prevenção de conflitos. (GOMES, 2013).

Segundo Gomes (2013), essas ações terminam por produzir ou reforçar estigmas que promovem o desdouro de crianças e adolescentes, suas famílias e da própria comunidade escolar como um todo. Com isso,

[...] se faz necessária a problematização de ações que revitimizem crianças e adolescentes, ou que reforcem a invisibilidade e estigmatização de sujeitos em situação de violência. A promoção de espaços participativos que envolvam conjuntamente profissionais, crianças, adolescentes e suas famílias, deve se dar a partir da comunicação e de uma escuta sensível ao Outro. Na elaboração ou recriação destes espaços de proteção, deve-se possibilitar a visibilidade destes seres em desenvolvimento como sujeitos de direitos humanos, ao facilitar o estabelecimento de novas possibilidades para construção de si mesmo. (GOMES, 2013, p. 118). 
Ao desenvolver uma pesquisa em 24 escolas estaduais e municipais em Salvador, Bahia, Gomes (2013) realizou observações sobre tais problemas diretamente no contexto escolar. A autora narra diversas situações de difíceis relacionamentos e de violência com que se deparou e que a marcaram profundamente.

Assim, por não terem as escolas pesquisadas tratado de maneira imediata situações envolvendo alunos e famílias de alunos, mais problemas foram gerados, tais como o abuso sexual continuado, a proliferação de doenças sexualmente transmissíveis (DSTs), entre outros.

Entre as situações vivenciadas e observadas por Gomes (2013), encontram-se as brigas não só entre meninos, mas também entre meninas, que utilizam as redes sociais para marcá-las nos horários reservados às aulas, dentro e fora da escola, chegando a filmar as agressões e divulgálas, divertindo-se com o que fizeram. Houve casos, segundo a autora, em que: "Professores abandonavam as salas [...] para não serem responsabilizados, [...] diretores não conseguiam dialogar, e sanções, punições e suspensões eram insuficientes [...]" (GOMES, 2013, p. 17-18).

Reportagens veiculadas pela mídia têm revelado o aumento dos índices da violência escolar e disseminado notícias sobre comportamentos agressivos, massacres, trotes irresponsáveis, bullying e ciberbullying, tragédias que têm, lamentavelmente, ganhado evidência. Mesmo nas universidades, embora não mais tão frequentes como já o foram, ainda acontecem trotes cruéis (SILVA, 2010).

Situações também preocupantes são as das vítimas típicas do bullying. Conforme Silva (2010), os padecentes são alunos que apresentam pouca habilidade de se relacionar, por serem tímidos ou reservados, e, por isso, são intimidados por seus agressores.

Utilizado também com fim de produzir sofrimento, tem crescido o ciberbullying ou bullying virtual. Ele intimida, prejudica adolescentes atacados por agressores que não têm sua identidade revelada. As vítimas sofrem assédio moral e dificilmente denunciam os fatos, alimentando a postura covarde dos autores (SILVA, 2010).

Dramas como esses trazem à tona a necessidade de seu enfrentamento, da discussão de ações, de repensar os métodos, de arriscar hipóteses, de serem feitas investigações, sempre com a finalidade de esclarecer, responder questões ligadas à violência, seus vínculos com a fragilidade do tecido social e suas devastadoras consequências (SILVA, 2010) pessoais e para o desenvolvimento local.

Porém, nem tudo o que se vê como situação negativa o é necessariamente. Além de ser uma forma de revelar o que está subjacente ao fenômeno, é oportunidade para novas formas de intervir social e educacionalmente. É por isso que o texto de Pedroza (2012) adverte:

Não são necessários que a diversidade cultural e os conflitos na escola entre adolescentes e adultos sejam vistos como algo negativo, destruidor. Pelo contrário, são formações particulares e não necessariamente hostis a tudo o que é diferente deles. (PEDROZA, 2012, p. 65).

Entendendo que o problema das relações interpessoais envolve ações mais amplas na definição do projeto político pedagógico da escola, propõe:

É necessário desenvolver no contexto escolar relações interpessoais que permitam uma integração das diversas áreas do conhecimento e das diferentes funções de cada membro da escola, reconhecendo a necessidade de superação da fragmentação do saber e dos fazeres, característica da escola tradicional. (PEDROZA, 2012, p. 79). 
A autora (2012) mostra, assim, a importância de se considerar o contexto mais amplo da escola, inclusive as divisões do conhecimento e do saber, toda a diversidade cultural nela existente para se trabalhar as relações interpessoais. Enfatiza a necessidade de se acolher todos de forma democrática e de firmar um compromisso constante de repensar o modo como são desenvolvidas as práticas profissionais, considerando-se que precisam ser "[...] formativas de sujeitos cidadãos mais felizes e envolvidos emocionalmente com as mudanças sociais" (PEDROZA, 2012, p. 82).

Fritzen (2009), por sua vez, enfatiza técnicas e exercícios práticos de dinâmicas de grupo com vistas a promover nas pessoas um mais alto conhecimento de si próprias e dos outros, relações mais integrativas e com os sentidos de solidariedade, credibilidade e interesse interpessoal. Discorre acerca da necessidade de se trabalhar a:

[...] modificação de atitudes, comportamento dos membros, relacionamento interpessoal. É preciso desinstalar a pessoa de seu individualismo, do seu egoísmo, e relacioná-la com os outros. O homem é essencialmente um SER COM, um ser de relação com os outros, para realizar-se, para amadurecer, e que sofre a pressão dos outros. As pessoas em geral têm pouca consciência disso e é algo que não se adquire através de conceitos teóricos, senão através de vivências que modifiquem essa mentalidade. (FRITZEN, 2009, p. 8).

Um desses entendimentos importantes para a mudança das práticas que envolvem as relações interpessoais na escola refere-se à questão dos direitos humanos e sociais. Para Cury (2011),

Declarar direitos é um recurso político-pedagógico que expressa um modo de conceber as relações sociais dentro de um país. É também um instrumento voltado à memória individual ou coletiva a fim de lembrar ou relembrar quem se esqueceu de tomar ciência do direito. (CURY, 2011, p. 567-8).

A conquista e a manutenção dos direitos humanos são cada vez mais um grande desafio na sociedade brasileira, o qual tem se tornado, crescentemente, mais penoso no ambiente escolar, resultando, muitas vezes, maior insegurança e perplexidade diante dos fatos adversos. Para enfrentá-los, uma proposta tem sido a oferta de oficinas pedagógicas em Direitos Humanos e a inclusão dessa temática na formação inicial e continuada dos profissionais da educação. Contudo, Monteiro e Pimenta ponderam:

O desenvolvimento de uma Educação em Direitos Humanos [...] é uma questão complexa, atravessada por tensões e desafios. Exige problematizar diferentes elementos do modo como hoje, em geral, concebemos nossa prática educativa. (MONTEIRO; PIMENTA, 2013, p. 153-4).

A Declaração Universal dos Direitos Humanos, adotada e proclamada pela Assembleia Geral das Nações Unidas, em 10 de dezembro 1948, estabelece a afirmação da liberdade, da igualdade e da universalidade. Desenvolveu-se tendo como referência básica a perspectiva da modernidade no tratamento dos Direitos Humanos. Articula questões relevantes sobre o tratamento dos direitos entre pessoas e diferentes grupos, levando em consideração aspectos socioculturais não observados, desprezados e relegados ao segundo plano. Problemas que afetam a sociedade como um todo e se mostram cada vez mais nítidos nos processos educativos, com a necessidade de preparo dos profissionais da educação para melhor enfrentá-los (MONTEIRO; PIMENTA, 2013).

A Constituição da República Federativa do Brasil, promulgada em 5 de outubro de 1988, estabelece em seu preâmbulo os objetivos necessários, que qualificam o Estado Democrático de direito brasileiro. Entre outros: 
[...] destinando a assegurar o exercício dos direitos sociais e individuais, a liberdade, a segurança, o bem-estar, o desenvolvimento, a igualdade e a justiça como valores supremos de uma sociedade fraterna, pluralista e sem preconceitos, fundada na harmonia social e comprometida, na ordem interna e internacional, com a solução pacífica das controvérsias [...]. (BRASIL, 1988).

Do ponto de vista conceitual, legal e institucional, houve avanços na concretização dos direitos sociais e individuais, ainda que falte muito para que eles sejam efetivamente uma realidade para todos. Há, por exemplo, ainda um bom número de crianças fora da escola. Problemas de ordem social e econômica, déficits de moradia e sua distância física em relação à escola estão na origem de evasões e repetências de alunos, do desinteresse familiar com respeito à educação escolar das crianças. Em que pesem tais desvios, o dever do Estado de cumprir com a observância de tais direitos não pode ser desvirtuado, sob pena de descumprimento das clausuras da Constituição da República, de 1988.

Por isso, pode-se afirmar que o direito à educação ainda está por se efetivar. Cury esclarece que:

[...] em um país como o Brasil, cumpre assinalar a existência de constituições estaduais, as leis orgânicas dos municípios, autônomas na sua competência. Elas podem explicitar um princípio geral, adequar à sua realidade e fazer avançar o direito à educação [...]. (CURY, 2011, p. 569-70).

A proclamação desse direito, entre outros, demarca o trilho do empenho a ser feito, sabendo-o fruto de constantes embates sociais. Ela impõe reflexão permanente e estímulo para rever o contexto em que as escolas se inserem atualmente. Diante desse desafio constante, cumpre buscar ações para reverter, inovar e criar possibilidades a fim de prevenir e enfrentar a violência escolar, que se contrapõe cotidianamente à conquista de tais direitos (CURY, 2011).

A relação entre a educação e as leis, muitas vezes, ocorre por veredas tortuosas, intrincadas, entremeadas de contradições, afrontando a dignidade da pessoa humana e impondo limites ao desenvolvimento soberano e democrático do país, ao que preconiza o preâmbulo da Constituição da República. (CURY, 2011).

O Estatuto da Criança e do Adolescente (ECA), instituído pela Lei n. 8.069, de 13 de julho de 1990, estabelece as referências que a educação escolar deve seguir para dar sua resposta à sociedade, para o que os profissionais responsáveis por ela devem voltar seu olhar:

[...] à percepção histórica da escola como espaço do castigo - a palmatória e a vara de marmelo, o grão de milho, copiar cem vezes "não devo responder a minha professora", ficar sem recreio - até muito pouco tempo institucional e reconhecido pela comunidade como recurso didático-pedagógico, mais recentemente configurado nas manifestações públicas e explícitas de desqualificação: uma violência historicamente situada [...]. (GOMES, 2013, p. 73-4).

A superação dessa pedagogia tradicional demanda a construção de um novo olhar para cumprir o dever constitucional de forma integrada ou articulada com a proteção dos direitos de crianças e adolescentes. Libertar a educação de características autoritárias e promover relações pessoais colaborativas, sob a luz do Estatuto da Criança e do Adolescente (ECA), pode contribuir para processos de mudanças e transformações sociais. Ao reconhecer na criança um sujeito de direito, estará a sociedade incorporando de fato uma nova percepção do aluno. Gomes acredita "[...] ser fundamental que a escola descubra o ECA e o incorpore no seu dia a dia" (GOMES, 2013, p. 75). 
A educação escolar encontra nas leis e no ECA fundamentos para mudar seu olhar a respeito do seu modus operandi. Uma visão mais humanista e solidária, o abandono de vez do autoritarismo e dos velhos métodos didático-pedagógicos condizem com o que a sociedade atual demanda em termos de eficiência social.

Mesmo episódicos e pontuais atos de agressão, desrespeito e violência afetam diretamente a vida nas escolas e geram incertezas quanto à possibilidade do desenvolvimento de relações interpessoais equilibradas. Oferecem, por outro lado, ensejos para propostas de inovação pela e na escola, o que remete a condições diversas de promoção do processo educativo.

Abramovay (2004) chama, contudo, a atenção para o fato de que experiências bemsucedidas ou inovadoras correm o risco de serem ineficazes ou ultrapassadas quando os estudos estabelecem termos comparativos controversos sobre qual das experiências pode ser considerada mais inovadora. Nesse sentido, a autora procura resgatar a percepção de inovação que os próprios sujeitos envolvidos têm quando falam de suas experiências/ações/projetos. Ela argumenta que "A inovação não é atemporal nem abstrata, mas adquire significado quando historicizada e contextualizada" (ABRAMOVAY, 2004, p. 34). Porém há ingredientes desse processo escolar inovador que ela faz questão de explicitar:

[...] tornarem-se mais abertas à participação dos jovens e da comunidade; interagirem com as práticas curriculares cotidianas da escola; terem caráter sistemático; incorporarem um maior número de alunos e professores e atentarem às especificidades dos jovens, tirando partido de seu potencial criativo e de sua disposição para o novo. (ABRAMOVAY, 2004, p. 56).

Entre as estratégias de superação usadas pelas chamadas escolas inovadoras, que integraram a pesquisa por ela coordenada, Abramovay cita: mecanismos de resolução em conjunto de problemas com a participação dos diversos sujeitos que compõem o ambiente escolar; abertura da escola nos fins de semana, permitindo desenvolver atividades e atrair a comunidade; disponibilização de espaços para jovens, adultos e instituições visando à resolução de conflitos; relação esporádica com o Conselho Tutelar (ABRAMOVAY, 2004).

Nas experiências pesquisadas, a autora ainda encontrou como orientação seguida: a habilidade de desenvolver estratégias integradas, participativas, flexíveis; a permissão para que se desenvolva um sentimento positivo de pertencimento ao espaço escolar público; a busca da superação do sentimento derrotista e o fornecimento de uma nova percepção do uso do espaço físico, da sociabilidade e do resgate da imagem da escola; a formação de laços voltados à edificação de uma cultura da não violência (ABRAMOVAY, 2004, p. 91).

As atividades realizadas no cotidiano escolar de forma simples, porém, significativa, que permitam envolver os alunos no compromisso e na busca de soluções para o enfrentamento de problemas na escola, podem levar à articulação de projetos, ampliação de parcerias e criação de estratégias, privilegiando o coletivo. Esse é um recurso considerado eficaz na superação das dificuldades no ambiente escolar; "[...] elemento essencial de um processo educativo em torno do ser cidadão, ainda concorre para a recuperação da credibilidade das escolas públicas" (ABRAMOVAY, 2004, p. 113).

O exercício do diálogo assume papel importante sob esse enfoque que privilegia o coletivo. Ele se torna ferramenta ou instrumento político essencial à reorganização das práticas cotidianas. A gestão desfaz-se de seus traços outrora centralizadores e assume uma lógica mais participativa ao estabelecer relações de respeito e equidade com todos da comunidade escolar e de: 
[...] diálogo, fator decisivo no processo de transformação da escola em instância de pertencimento e identidade. Freire afirma que não se pode pensar pelos outros nem para os outros nem sem os outros. A significação do diálogo está no fato de que os sujeitos dialógicos crescem um com o outro. (ABRAMOVAY, 2004, p. 95).

No ambiente onde antes imperava a lei do silêncio, surge o diálogo capaz de despertar no jovem a vontade genuína de participar. À medida que descobre mais de si e do outro, o sujeito compartilha saberes com o grupo, estreita as relações de amizade, mostra-se favorável a discutir amplamente atitudes que vão repercutir para o bom clima escolar e, consequentemente, para a redução da violência e a revalorização da educação.

Ainda que se saiba que uma sociedade violenta produz efeitos nas relações interpessoais que acontecem no interior da escola, a partir dos relatos dos achados nas experiências estudadas, depreende-se que uma escola inovadora pode criar condições favoráveis ao desenvolvimento de relações interpessoais mais harmônicas, já que ela procura lançar um novo olhar sobre o padrão formativo do aluno.

Iluminada por propósitos claros, previamente organizados, visando aos anseios da instituição, a escola inovadora define estratégias que permitam condições de participação de todos os sujeitos que compõem a comunidade escolar. Ela é, assim, fonte motivadora para a transformação social, a redução e prevenção da violência que interfere no clima escolar, nas relações interpessoais e na qualidade da educação.

O professor, ao buscar desenvolver vínculos sociais em sala de aula, depara-se com alunos com personalidades e características diferentes. A percepção que o professor constrói de cada aluno e instintivamente transmite a outros por meio de suas ações ou atitudes pode refletir na compreensão que os alunos têm dele, de si, e dos colegas.

É comum observar, no cotidiano da sala de aula, que tanto professores como alunos estabelecem, por observação, critérios em relação ao professor favorito, ao que trabalha com afeição, ao que é exigente, ao aborrecido, ao que engabela suas aulas, ao que apenas espera cumprir seu horário... Da mesma forma, os alunos também constroem a percepção sobre seus colegas: aquele de maior destaque na turma, o mais elogiado pelos professores, o mais alegre, o mais amigo, aquele que ninguém quer no grupo, o tímido que conversa pouco, o diferente, o que é tido como grosseiro etc. (MARTINELLI; SCHIAVONI, 2009).

O conjunto das observações formadas pelos alunos mostra que eles desenvolvem sentimentos, raciocínios sobre como os outros os veem, como o professor observa cada aluno, se ele é aceito ou não etc. Quando o sentimento é negativo, gera baixa autoestima no aluno. Este, quando rejeitado, por vezes busca se livrar dessa condição, aguardando uma possibilidade que the permita interagir e novamente fazer parte do grupo e sentir-se aceito.

Uma criança que não tem sucesso na escola vai acumulando experiências de fracasso sucessivamente, o que pode levá-la a se perceber negativamente em relação aos demais. Sua aprendizagem pode se tornar mais prejudicada à medida que tem dificuldade para fazer amigos, relacionar-se e, aos poucos, pode ficar à margem do grupo, formando uma imagem deformada de si mesma. (MARTINELLI; SCHIAVONI, 2009, p. 334).

Os resultados trazidos pela pesquisa realizada por Martinelli e Schiavoni (2009) representam outro caminho para se refletir sobre as interações no ambiente escolar, sua relação com o ensinoaprendizagem e como a afetividade se relaciona ao modo de professores e alunos se envolverem com a ampla diversidade com que se confrontam no dia a dia da sala de aula. Apagam-se as linhas divisórias traçadas de forma simplista entre os que são bons e os que não o são e se aceita 
o desafio de reverter situações, desconstruindo o lugar de alguns para reconstruir um lugar de todos (MARTINELLI; SCHIAVONI, 2009).

A pesquisa de Insfrán e Souza Filho (2011) procura descobrir possíveis causas psicossociais para o sucesso e insucesso de estudantes, tendo realizado entrevistas com 30 ex-alunos de um pré-vestibular comunitário do interior do Estado do Rio de Janeiro. Os autores constataram a existência de dois modelos representacionais: os estudantes bem-sucedidos centrados na ação, e os malsucedidos, nos resultados (INSFRÁN; SOUZA FILHO, 2011, p. 345). Verificou-se na composição de grupos e sua dinâmica que alunos bem-sucedidos manifestaram apoio aos professores enquanto alunos malsucedidos manifestaram resistência e afastamento nas relações com os educadores. Os autores assim se exprimiram:

\begin{abstract}
Sabemos que para muitos brasileiros a experiência educacional é tão relevante para o sucesso pessoal quanto tem sido marcada por adversidades internas e externas. Acreditamos que parte das dificuldades internas resida em superar certo bloqueio ou conduta de retraimento/ inibição em relação ao enfrentamento da situação ensino-aprendizagem, consigo mesmo, com o professor e os colegas. Estes últimos que eventualmente são mais bem-sucedidos na realização das tarefas, possivelmente gerem ansiedade e sentimentos desagradáveis de frustração entre os demais, não tão bem sucedidos. Trata-se de constituir uma pedagogia realista de superação gradual de dificuldades, focalizando mais nas ações empreendidas. Ao lado disso, os estudantes bem-sucedidos poderiam aprender a lidar melhor com colegas que têm dificuldades, através de tarefas que permitam atividades comuns [...]. (INSFRÁN; SOUZA FILHO, 2011, p. 358-9).
\end{abstract}

Rodrigues, Dias e Freitas analisaram um grupo homogêneo quanto às características do contexto cultural e socioeconômico, com objetivo de dar importância a uma intervenção voltada a minimizar problemas e conflitos interpessoais. Para as autoras:

[...] Programas promotores de competências socioemocionais infantis são de grande valia para fortalecer o relacionamento interpessoal, pois a aprendizagem de comportamentos e modos de pensar na infância produz impacto na trajetória da vida adulta. (RODRIGUES; DIAS; FREITAS, 2010, p. 838).

Tal como foi encontrado nos trabalhos citados anteriormente, as autoras também concordam que trabalhar as relações interpessoais na escola por meio do diálogo, da formação e manutenção de grupos que compõem o ambiente escolar é fundamental para superar e solucionar problemas comportamentais e promover o desenvolvimento do ser humano.

Elas observam a necessidade de se promover programas permanentes de capacitação e educação, levando-se em conta todos os sujeitos que compõem o ambiente escolar.

\title{
3 CONSIDERAÇÕES FINAIS
}

Os textos selecionados para esta revisão de literatura permitiram reconhecer que a supressão das barreiras à comunicação e promoção do diálogo e do entendimento, visando à melhoria das relações interpessoais, têm se mostrado como grandes desafios enfrentados no dia a dia da escola. Foram, no entanto, assertivos em afirmar que é primordial que se atenda a essa demanda por se tratar de questão crucial para o processo de ensino-aprendizagem, a educação dos alunos e o desenvolvimento local.

Além dos textos selecionados, é possível encontrar outras contribuições para a elevação da reflexão a respeito desses desafios. Entre os resultados de pesquisas analisados, sobressaiu 
a importância dada à atuação do professor como agente transformador no processo de ensino-aprendizagem.

Viu-se, também, que a questão das relações interpessoais na escola se conecta com outras relacionadas ao atendimento das necessidades educativas fundamentais que visam ao desenvolvimento pessoal e intelectual de cada aluno. Nesse sentido, as propostas educacionais que propiciaram essa reflexão, nesta revisão, precisam ser mais estudadas, inclusive empiricamente, para explorar as mútuas relações entre fenômenos de diferentes ordens, que ocorrem no espaço escolar.

Para tanto, algumas pesquisas se destacaram como contribuição para tais investigações: o trabalho coordenado por Abramovay (2004), sobre experiências desenvolvidas em quatorze escolas públicas; o de Gomes (2013), acerca das observações realizadas em 24 escolas estaduais e municipais em Salvador, Bahia; o de Martinelli e Schiavoni (2009), a respeito da percepção do aluno sobre sua interação com o professor; e o de Insfrán e Souza Filho (2011), concernente às representações antecipatórias em situações educacionais adversas.

Houve consenso entre os autores consultados sobre a importância do exercício do diálogo e do enfoque que privilegia a necessidade de dar atenção à dimensão do coletivo, ambos vistos como ferramentas ou instrumentos políticos e pedagógicos essenciais para a reorganização de práticas escolares cotidianas. Destacou-se, igualmente, a consideração da escola como instituição capaz de motivar e agir a favor da transformação social e do desenvolvimento local. Para tanto, cresce a relevância da discussão dos aspectos psicossociais das relações interpessoais que envolvem a comunidade escolar e suas relações com seu entorno.

Finalmente, é importante dizer que muitos dos subsídios oferecidos pela literatura consultada e analisada deixaram de ser aqui registrados por motivo de espaço. Outra consideração final a ser feita refere-se à constatação de que, a despeito da grande importância e representatividade dos estudos selecionados para esta revisão, o tema das relações interpessoais na escola, por ser muito instigante e se encontrar aberto a reflexões com base em ângulos diversos, cobre uma gama diferenciada e rica de estudos, que merecem ser conhecidos e também referenciados.

\section{REFERÊNCIAS}

ABRAMOVAY, Miriam; NUNES, Maria Fernanda Rezende; ANDRADE, Eliane Ribeiro; FARAH NETO, Miguel; MUNIZ, Maria Ângela Carvalho de Oliveira; CASTRO, João Paulo Macedo e; LEITE, Ana Maria Alexandre; GIL, Luiz Carlos. Escolas inovadoras: experiências bem-sucedidas em escolas públicas. In: ABRAMOVAY, Miriam (Coord.). Brasília: Unesco; Ministério da Educação, 2004. 124 p.

ANTUNES, Celso. Relações interpessoais e autoestima: a sala de aula como um espaço de crescimento integral. 10. ed. Petrópolis, RJ: Vozes, 2014.

ANTUNES, Celso. A prática dos quatro pilares da Educação na sala de aula. 3. ed. Petrópolis, RJ: Vozes, 2013. (Coleção na Sala de Aula).

BRASIL. Presidência da República. Constituição da República Federativa do Brasil, 1988. Disponível em: http://www.planalto.gov.br/ccivil_03/Constituicao/Constituicao.htm. Acesso em: 18 maio 2021.

BRASIL. Lei n. 8.069, de 13 de julho de 1990. Dispõe sobre o Estatuto da Criança e do Adolescente e dá outras providências. Brasília-DF, 1990. Disponível em: http://www.planalto.gov.br/ccivil_03/leis/ I8069compilado.htm. Acesso em: 18 maio 2021. 
CHAUÍ, Marilena. Uma ideologia perversa. Folha de S. Paulo, Caderno +mais!, São Paulo, 14 mar. 1999. Disponível em: https://www1.folha.uol.com.br/fsp/mais/fs14039904.htm. Acesso em: 3 jan. 2019.

CURY, Carlos Roberto Jamil. A educação como desafio na ordem jurídica. In: LOPES, Eliane Marta Teixeira; FARIA FILHO, Luciano Mendes; VEIGA, Cynthia Greive. (Org.). 500 anos de educação no Brasil. 5. ed. Belo Horizonte: Autêntica, 2011.

FRIEDMANN, Adriana. Dinâmicas criativas: um caminho para a transformação de grupos. Petrópolis, RJ: Vozes, 2004.

FRITZEN, Silvino José. Exercícios práticos de dinâmica de grupo (Ir. Amadeu Egydio). 38. ed. Petrópolis, RJ: Vozes, 2009.

GOMES, Celma Borges (Coord.). Violência nas escolas: uma realidade a ser transformada. Curitiba: Juruá, 2013.

INSFRÁN, Fernanda Fochi Nogueira; SOUZA FILHO, Edson Alves de. Representações antecipatórias em situações educacionais adversas: um estudo de um programa de pré-vestibular comunitário. Ensaio: Avaliação e Políticas Públicas em Educação, v. 19, n. 71, p. 345-62, 2011.

LEITE, Camila de Queiroz. Delinquência e violência entre adolescentes de classe média de Brasília. 2004. 56 p. Monografia (Graduação em Psicologia) - Faculdade de Ciências da Saúde, Centro Universitário de Brasília [UniCeub], Brasília-DF, 2004.

MARTINELLI, Selma de Cássia; SCHIAVONI, Andreza. Percepção do aluno sobre sua interação com o professor e status sociométrico. Estudos de Psicologia, Campinas, v. 26, n. 3, p. 327-36, 2009.

MARX, Karl. Teses sobre Feuerbach. [1845]. Moscou; Lisboa: Edições Progresso, 1982. Disponível em: https://www.marxists.org/portugues/marx/1845/tesfeuer.htm. Acesso em: 18 maio 2021.

MARX, Karl; ENGELS, Friedrich. Feuerbach. Oposição das concepções materialista e idealista. In: MARX, Karl; ENGELS, Friedrich. A ideologia alemã. Moscou; Lisboa: Edições Progresso, 1982. [Capítulo primeiro]. Disponível em: https://www.marxists.org/portugues/marx/1845/ideologia-alema-oe/index.htm. Acesso em: 18 maio 2021.

MENTIS, Mandia. (Coord.). Aprendizagem mediada dentro e fora da sala de aula. Tradução de José Francisco Azevedo. São Paulo: Ed. Senac, 1997. 202 p.

MICHAUD, Y. A violência. S. Paulo: Ática Ed., 1989.

MONTEIRO, Aida; PIMENTA, Selma Garrido. Educação em Direitos Humanos e formação de professores(as). São Paulo: Cortez Editora, 2013.

MORAES, Sílvia Elizabeth. Interdisciplinaridade e transversalidade mediante projetos temáticos. Revista Brasileira de Estudos Pedagógicos, v. 86, n. 213/214, 2007.

PARO, Vitor Henrique. Gestão escolar, democracia e qualidade no ensino. São Paulo: Ática, 2007.

PEDROZA, Regina Lúcia Sucupira. Relações interpessoais: abordagem psicológica. 4. ed. atual. e rev. Cuiabá: Universidade Federal de Mato Grosso; Brasília: Ministério da Educação, Secretaria de Educação Profissional e Tecnológica, Rede e-Tec. 2012.

RODRIGUES, Aroldo. Psicologia social. 27. ed. Petrópolis: Vozes, 2009. 
RODRIGUES, M. C; DIAS, J. P.; FREITAS, M. F. L. Resolução de problemas interpessoais: promovendo o desenvolvimento sociocognitivo na escola. Psicologia em Estudo, Maringá, v. 15, n. 4, p. 831-9, 2010.

SILVA, Ana Beatriz B. Bullying: mentes perigosas nas escolas. Rio de Janeiro: Objetiva, 2010.

VIGOTSKI, L. S. Manuscrito de 1929. Educação \& Sociedade, Campinas, ano XXI, n. 71, p. 21-44, jul. 2000.

\section{Sobre as autoras:}

Samira Fakhouri Baia: Mestre pelo Programa de Pós-Graduação em Gestão Social, Educação e Desenvolvimento Local do Centro Universitário Una, Belo Horizonte, MG. Graduada em Direito e em Administração pelo Centro de Ensino Superior do Amapá (instituição). Atua como professora de Artes no ensino fundamental II e em cursos de educação profissional em Administração. E-mail: baia.samira@gmail.com, Orcid: http://orcid.org/0000-0002-3203-9693

Lucília Regina de Souza Machado: Pós-doutora em Sociologia do Trabalho pelo Institut des Recherches sur les Sociétés Contemporaines (Iresco), Paris. Doutora em Educação pela Pontifícia Universidade Católica de São Paulo. Mestre em Educação e Graduada em Ciências Sociais pela Universidade Federal de Minas Gerais. Professora titular aposentada da Faculdade de Educação da Universidade Federal de Minas Gerais (UFMG). Atua principalmente nos seguintes temas: trabalho, teoria da atividade, formação humana, pedagogia do trabalho, educação, escola unitária, trabalho-educação, educação profissional e tecnológica, gestão social, desenvolvimento local, políticas sociais e políticas públicas. E-mail: luciliamachado2014@gmail.com, Orcid: http://orcid.org/0000-0001-9029-3019 
